\title{
Computational analysis of hydrocarbon combustion
}

\author{
P Karthikeyan ${ }^{1}$, S.Madhavan ${ }^{2}$, SM Silambarasan ${ }^{2}$, M.Haja Najibudeen ${ }^{2}$ \\ ${ }^{1}$ Assistant Professor, Department of Aeronautical Engineering, Paavai Engineering College, Namakkal, India \\ ${ }^{2}$ UG scholar, Department of Aeronautical Engineering, Paavai Engineering College, Namakkal, India
}

\begin{abstract}
Combustion of fuel with oxidizer provides continuous power for the vehicles to move forward. Welldesigned combustor produces complete combustion, where water and carbon dioxide are the stable products. Incomplete combustion additionally produces more emission in the form of carbon monoxide and nitrogen oxides due to factors like poor mixing of the air and fuel or insufficient excess air. Therefore in order to understand the importance of various parameters which affects the combustor performance and to design the effective combustor, which delivers high combustion efficiency, it is very essential to study the combustor using CFD techniques, performed using ANSYS Fluent software. Computational or CFD methodology is used here to perform combustion simulation on the typical combustor models, where hydrocarbon like kerosene (Jet fuel) is burned with incoming air at high velocity. Computational models are created with pre-processor such as Gambit and subsequent processing and post processing with Ansys Fluent as the software. Suitable turbulent model, chemical model and physical models are enabled to analyse and plot the mass fraction of various chemical species along the length of the combustor. Fuel Additives are used to evaluate the peak temperature. The combustion efficiency of this hydrocarbon combustion is evaluated using this numerical tool.
\end{abstract}

\section{INTRODUCTION}

This chapter will provide a basic introduction to scramjet technology by presenting the definition, current status of scramjet engines. historical timeline, possible applications, and the current status of scramjet engines.

\section{DEFINITION OF SCRAMJET ENGINE}

To give the meaning of a scramjet motor, the meaning of a ramjet motor is first essential, as a scramjet motor is an immediate relative of a ramjet motor. Ramjet motors have no moving parts,

rather working on pressure to ease back freestream supersonic air to subsonic velocities, in this manner expanding temperature and pressing factor, and afterward combusting the compacted air with fuel. In conclusion, a spout speeds up the exhaust to supersonic velocities, bringing about push. Figure 1 beneath shows a two dimensional schematic of a ramjet motor. Because of the deceleration of the freestream air, the pressing factor, temperature and thickness of the stream entering the burner are "impressively higher than in the freestream". At flight Mach quantities of around Mach 6 , these builds make it wasteful to keep on easing back the stream to subsonic rates. Consequently, if the stream is not, at this point eased back to subsonic rates, yet rather just eased back to satisfactory supersonic rates, the ramjet is then named a 'supersonic ignition ramjet,' bringing about the abbreviation scramjet. Figure 2 beneath shows a twodimensional schematic of a scramjet motor.

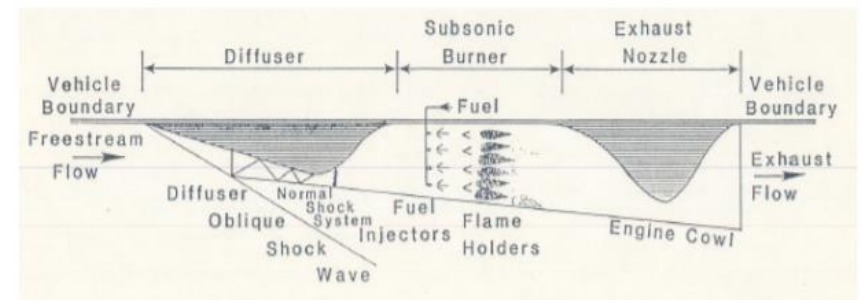

\section{APPLICATIONS OF SCRAMJET ENGINES}

There is a scope of potential applications for scramjet motors, including rocket drive, hypersonic cruiser drive, and some portion of an organized space assessments framework Figure 1.3 underneath shows the rough exhibition regarding motor explicit drive and Mach number for different sorts of drive frameworks [7]. It very well may be seen that at Mach numbers higher than roughly 6-7, the just accessible impetus frameworks are rockets and scramjets. Contrasted with rockets, scramjets have a lot higher explicit motivation levels; in this manner, it is clear why it is favourable to build up the scramjet, in the event that hence as it were. In spite of rockets, scramjets don't need that an 


\section{International Advanced Research Journal in Science, Engineering and Technology}

Vol. 8, Issue 5, May 2021

\section{DOI: $10.17148 /$ IARJSET.2021.8588}

oxidizer be continued board the airplane as it is an air breathing motor, gathering oxygen from the environment [7]. This reduction the necessary load of the general impetus framework also, fuel, bringing about a higher reasonable payload weight or expanded reach. There are different reasons that the advancement of the scramjet is worthwhile also. Air breathing motors produce higher motor proficiency, have a more drawn out fuelled reach, have the capacity for push regulation to guarantee effective activity, have higher mobility, and are totally reusable [7].

Figure 1.4 showcases a subjective outline of the impetus alternatives dependent on the flight Mach number [7]. The bend addresses the inexact elevation needed to work at a given flight Mach number just as the required drive framework. Likewise appeared on this graph is a general limit between the two essential fuel alternatives for scramjets: hydrocarbons and hydrogen. However Walrus presumes that as far as possible for hydrocarbons is between Mach 9 and 10 rather than Fry's chart showing roughly 8, the overall agreement is that hydrogen fuel ought to be utilized for air breathing flight quicker than Mach 8-10, due toits "higher cooling limit" and its "quicker responses" [7]. However hydrogen can perform at higher rates over the hydrocarbon furthest breaking point, Curran states that with current abilities the hydrogenfueled scramjet will just offer "satisfactory execution to about Mach 15" [2]. Concerning the space access application for scramjet innovation, Townsend contends, explicitly, that there are numerous benefits in applying the scramjet as the drive framework for the second phase of a two-stage-to-circle (TSTO), hydrocarbonpowered aviation plane. He clarifies that it would accommodate a little TSTO vehicle just as a little single-stage-tocircle (SSTO) vehicle or military hypersonic cruiser that utilizes a hydrocarbon- filled scramjet. Fry clarifies that the reasoning for hypersonic rocket capacity lies in the way that a Mach 6-8 rocket expands the conceivable reach inside a given flight time, or comparatively, diminishes the flight time needed for a given reach [7]. In outline, the objective of scramjet advancement is to give hypersonic vehicles a more effective option in contrast to rockets. The vehicle that could most rapidly profit by current scramjet research is the journey rocket; notwithstanding, a hypersonic cruiser airplane that is an option in contrast to conventional turbojet transportation for regular citizen or military 9 application could likewise be a not very inaccessible probability. Scramjets could likewise be utilized related to rockets for space launchers, subsequently requiring less ready oxidizer for transport to space

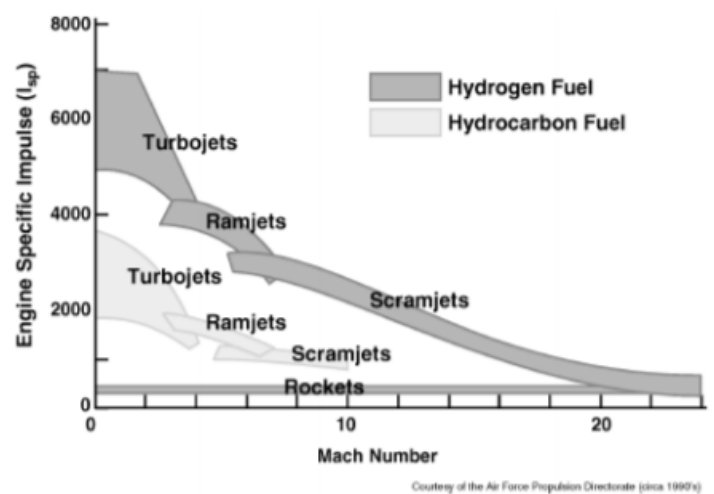

\section{Current Scramjet Engine Technology Challenges}

Figure 1.5 beneath is a decent rundown of the current challenges in the advancement of the scramjet motor. There are three fundamental zones that these issues lay in, specifically Air Inlet, Combustor, and Structures and Materials. Issues inside these territories fluctuate from delta beginning issues to the innate trouble of the start of the fuel in a supersonic stream, as the chance of disappointment exists anyplace from the fuel not lighting to the chance that the start could happen outside of the combustor due to the exceptional speed of the air in the motor. Furthermore, structures that can withstand the limit temperatures experienced during hypersonic flight joined with the extra temperature

experienced during ignition are essential. Notwithstanding the current specialized difficulties of scramjet advancement, there is another space of scramjet improvement which merits consideration. In spite of the wide scope of uses conceivable with scramjet innovation, the vehicle should initially be pushed to a sufficiently high Mach number for the scramjet to begin. This requires, contingent upon the required 


\section{International Advanced Research Journal in Science, Engineering and Technology}

Vol. 8, Issue 5, May 2021

DOI: $10.17148 /$ IARJSET.2021.8588

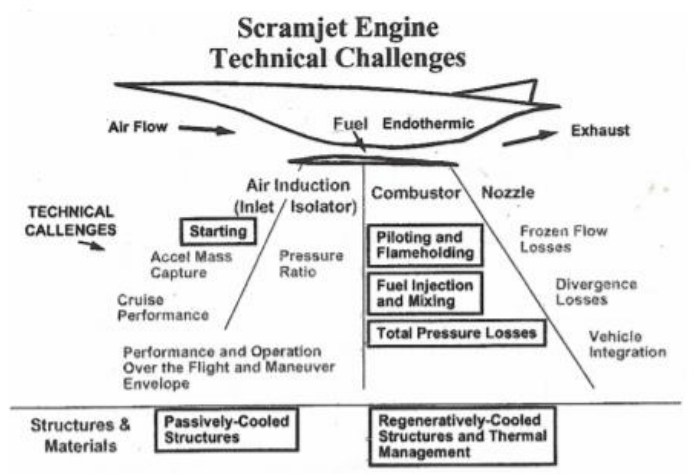

application, a couple extra impetus frameworks to drive the vehicle to the required scramjet start speed. Current scramjet plans focus on the beginning of supersonic burning to be between Mach 5 and $6[1,7,8]$. In request to limit the weight and intricacy of having different impetus frameworks, a double mode ramjet/scramjet is frequently proposed. Notwithstanding, if the essential scramjet beginning Mach number is decreased, a decrease in the quantity of required extra drive frameworks is conceivable, as the hole is connected between the greatest conceivable speed of the low speed engine(s) and the scramjet start speed. This would enjoy direct benefits from the coming about decrease in general vehicle weight, the lower mass portion needed for the drive framework (in this manner coming about in more accessible payload weight), and less frameworks that should work in progression dependably, in this way expanding in general vehicle wellbeing. The focal point of this undertaking is to address this issue of decreasing the beginning Mach number.

\section{HYPERSONIC PROPULSION}

gives high push and low weight for hypersonic flight vehicles. In contrast to a traditional turbojet motor or ramjet motor, a scramjet motor has no complex moving parts. It comprises of a diffusor at delta, spout at the exit and a combustor having a fuel injector, and fire holder (as featured from Figure A) The ignition chamber comprises of various sorts of fuel infusion framework (cross over, equal or calculated infusion plot), fire adjustment component and fuel start for the maintained burning When a scramjet motor mounted on a fast airplane, while pushing ahead, huge amounts of wind stream are drawn inside the motor through the gulf. The approaching air gets decelerated when going through the isolator area, and the unique pressing factor gets changed over into a higher static pressing factor. This high pressing factor, additionally called as slam impact works with in adding the warmth to the approaching air inside the burning chamber, without the requirement for having the different blower framework. In the burning chamber, fuel is appropriately blended in with the air at a sub-atomic level for appropriate start. Fire holders in the combustor help in settling the cycle of supersonic ignition. While consuming happens in subsonic mode in the ramjet motor $(\mathrm{M}<1)$, it happens totally in supersonic mode $(M>1)$ in the scramjet motor. After the ignition chamber, the hot fumes gas goes through a hypersonic spout, where the stream is sped up to a high Mach number. As the spout leave speed is higher than the free stream speed, drive force is made by Newton's second law which creates push in the forward bearing.

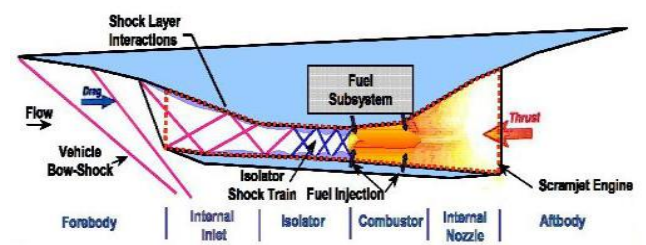

HYDROCARBON COMBUSTORCFDMODEL

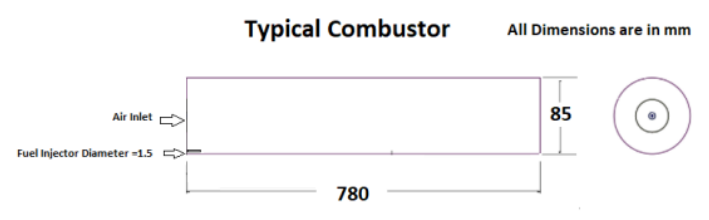




\section{CFD MESHING}

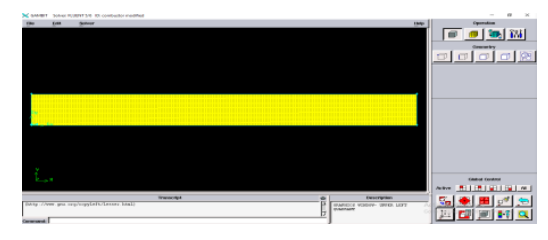

\section{Boundary Conditions}

- Inlet velocity for Air : $100 \mathrm{~m} / \mathrm{s}$

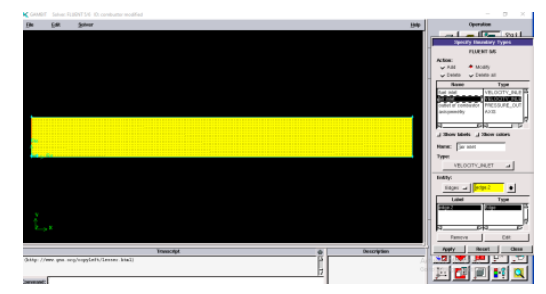

- Inlet Temperature for Air : $300 \mathrm{~K}$

- Species mass fraction for oxygen $=0.23$

- Inlet velocity for Fuel: $80 \mathrm{~m} / \mathrm{s}$

- Inlet Temperature for Fuel: $300 \mathrm{~K}$

- Species a mass fraction for

- Kerosene, $\mathrm{C} 12 \mathrm{H} 26=1$

With additive, Ethanol $=>$ Species a mass fraction for

- Kerosene, C12H26= 0.9

- Species a mass fraction for

- Ethanol, $\mathrm{C} 2 \mathrm{H} 5 \mathrm{OH}=0.1$

\section{ANSYS Fluent problem Setup:}

- In your paper title, if the words "that utilizes" can precisely supplant Solver Type: Pressure based

- $\quad$ Solver Time: Steady state

- $\quad$ Energy condition empowered

\section{Species transport model}

Volumetric combustion with Kerosene fuel as Mixture MateriaL

Additive used: Ethanol Turbulent chemical interaction : Eddy-dissipation Method

\section{Chemical Equation:}

$\mathrm{C} 12 \mathrm{H} 26+18.5(\mathrm{O} 2+3.76 \mathrm{~N} 2) 12 \mathrm{CO} 2+13 \mathrm{H} 2 \mathrm{O}+18.5(3.76 \mathrm{~N} 2)+$ Heat of Combustion

CFD results (For both Kerosene fuel with and without AdditivesTemperature Contour- Combustor without Additive

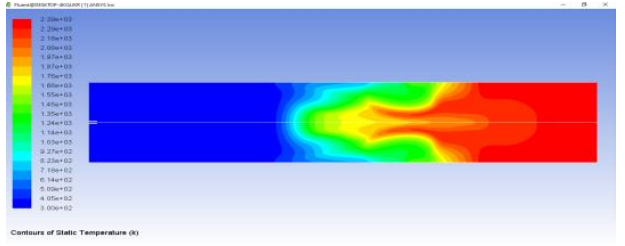


International Advanced Research Journal in Science, Engineering and Technology

Vol. 8, Issue 5, May 2021

DOI: $10.17148 /$ IARJSET.2021.8588

Temperature Contour- Combustor with Additives

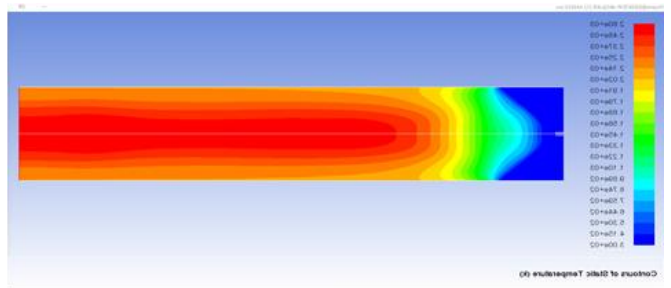

Combustor with Additive $=$ Increase in Peak Temperature $=210 \mathrm{~K}$

Velocity Contour- Combustor without Additive

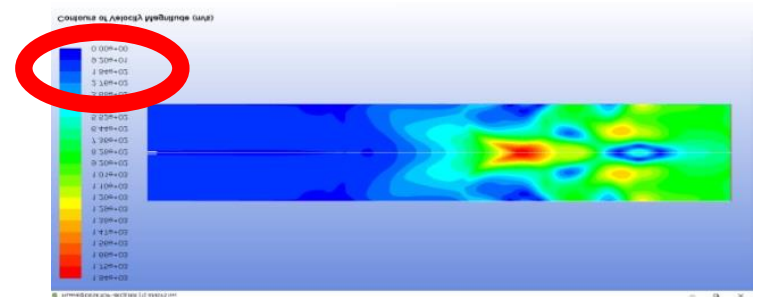

Velocity Contour- Combustor with Additive

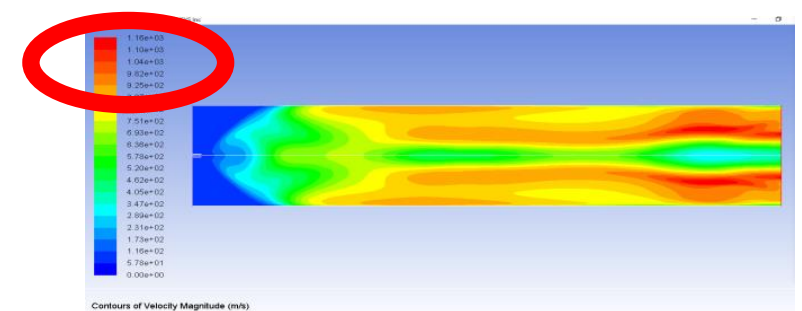

Combustor with Additive $=$ Increase in Peak Temperature $=210 \mathrm{~K}$

Combustion Efficiency

Combustion efficiency,

\begin{tabular}{|c|c|}
\hline $\begin{array}{l}\text { Mass-Weighted Auerage } \\
\text { Mass fraction of c12h23 }\end{array}$ & \\
\hline 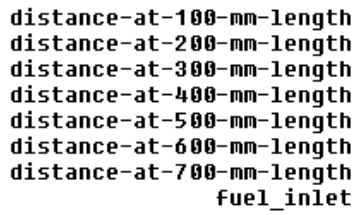 & $\begin{array}{r}0.077798258 \\
0.077821775 \\
0.076505163 \\
0.048120209 \\
0.029458273 \\
0.020754921 \\
0.015271109 \\
1\end{array}$ \\
\hline Net & 0. 05961343 \\
\hline $\begin{aligned} & \text { Flow Rate } \\
& \text { Mass fraction of c12h23 }\end{aligned}$ & $(\mathrm{kg} / \mathrm{s})$ \\
\hline 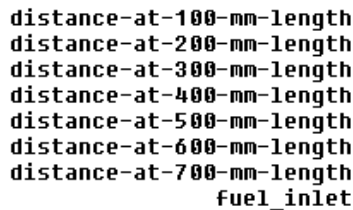 & $\begin{array}{r}-0.81538343 \\
-0.81567953 \\
-0.86643774 \\
-0.50575745 \\
-0.32598494 \\
-0.21750369 \\
-0.16055434 \\
0.81558776\end{array}$ \\
\hline & -2.8312134 \\
\hline
\end{tabular}

Combustion Efficiency

Combustion efficiency, $\eta \mathbf{b}$

$\eta=\underline{\text { (Mass of Injected fuel }- \text { Mass of fuel at outlet of combustor) }}$

Mass of Injected fuel

Combustion efficiency, $\eta$ b- Combustor without Additive 


\section{International Advanced Research Journal in Science, Engineering and Technology}

Vol. 8, Issue 5, May 2021

DOI: $10.17148 / I A R J S E T .2021 .8588$

At $700 \mathrm{~mm}$ length, (Nearly the end of the combustor)

- Mass of Injected fuel $=0.81558 \mathrm{Kg} / \mathrm{s}$

- Mass of fuel at section $7=0.16005 \mathrm{Kg} / \mathrm{s}$

- $\eta \mathrm{b}=(\underline{0.81558-0.16005)}=80.37 \%$

0.81558

The combustion efficiency is only $80.37 \%$

Combustion efficiency, $\eta \mathrm{b}$ - Combustor with Additive

At $300 \mathrm{~mm}$ length, (Nearly the middle of the combustor)

- Mass of Injected fuel $=0.5811 \mathrm{Kg} / \mathrm{s}$

- Mass of fuel at section $7=0.0077 \mathrm{Kg} / \mathrm{sp}$

$\eta \mathrm{b}=\underline{(0.5811-0.0077)}=98.67 \%$

0.5811

The combustion efficiency is $98.67 \%$

The combustion efficiency is $99.77 \%$ at $400 \mathrm{~mm}$ length of the combustor.

\section{CONCLUSION}

CFD models are created using Gambit software, which is fine meshed and with defined boundary conditions (PreProcessing)Processing and Post - Processing are carried out using Ansys fluent software, with turbulent and chemical model enabled for species transport Kerosene (Jet fuel) is used in case I and Kerosene mixed with $10 \%$ Ethanol (fuel additive) is used in case II to analyse this hydro carbon combustion The peak temperature obtained in fuel with additive is higher than the case with fuel alone

Temperature obtained in combustor with kerosene only $=2390 \mathrm{~K}$

Temperature obtained in combustor with kerosene + Ethanol $=2600 \mathrm{~K}$

\section{REFERENCES}

1. McDaniel et al [1991] "Experimental study of backward step combustor of dual transverse injection model " AIAA.

2. K.M. Pandey, A.P. Singh (2012) "Numerical Simulation of Combustion chamber without cavity at Mach 3.12": International Journal of Soft Computing and Engineering (IJSCE).

3. N. N. Fedorova, M. A. Goldfeld and Yu. V.Zakharova (2019) "Experimental and numerical analysis of hydrogen jet autoignition in backwardfacing-step-stabilized model scramjet combustor "Research Paper.

4. E. Jeong and I.-S. Jeung (2005) "Numerical Simulation Study on Cavity-Enhanced-Supersonic Combustion of Upstream Fuel Injection": 5th Asia-Pacific Conference on Combustion

5. Adela Ben-Yakar and Ronald K. Hanson (2001) "Cavity Flame-Holders for Ignition and Flame Stabilization in Scramjets: An Overview": JOURNAL OF PROPULSION AND POWER.

6. M Deepu, S S Gokhale, S Jayaraj, (2007) "Recent Advances in Experimental and Numerical Analysis of Scramjet Combustor Flow Fields": JOURNAL OF PROPULSION AND POWER.

7. Ronald S. Fry (2004) "A Century of Ramjet Propulsion Technology Evolution": JOURNAL OF PROPULSION AND POWER.

8. Aqheel Murtuza Siddiqui , G.M. Sayeed Ahmed (2013) “Design and Analysis on Scramjet Engine Inlet”: International Journal of Scientific and Research Publications.

9. Hongbo Wang, Zhenguo Wang, Mingbo Sun, Ning Qin (2013)" Large eddy simulation-based studies of jet-cavity interactions in a supersonic flow": Acta Astronautica.

10. Mohammad Ali, Toshi Fujiwara, Joseph E. Leblanc (1999) "Influence of main flow inlet configuration on mixing and flame holding in transverse injection into supersonic 